\title{
Perivascular Fibroblasts Form the Fibrotic Scar after Contusive Spinal Cord Injury
}

\author{
Cynthia Soderblom, Xueting Luo, Ezra Blumenthal, Eric Bray, Kirill Lyapichev, Jose Ramos, Vidhya Krishnan, \\ Catherine Lai-Hsu, Kevin K. Park, Pantelis Tsoulfas, and Jae K. Lee \\ University of Miami, The Miami Project to Cure Paralysis, Department of Neurological Surgery, Miami, Florida 33146
}

Injury to the CNS leads to formation of scar tissue, which is important in sealing the lesion and inhibiting axon regeneration. The fibrotic scar that comprises a dense extracellular matrix is thought to originate from meningeal cells surrounding the CNS. However, using transgenic mice, we demonstrate that perivascular collagen $1 \alpha 1$ cells are the main source of the cellular composition of the fibrotic scar after contusive spinal cord injury in which the dura remains intact. Using genetic lineage tracing, light sheet fluorescent microscopy, and antigenic profiling, we identify collagen $1 \alpha 1$ cells as perivascular fibroblasts that are distinct from pericytes. Our results identify collagen $1 \alpha 1$ cells as a novel source of the fibrotic scar after spinal cord injury and shift the focus from the meninges to the vasculature during scar formation.

\section{Introduction}

The scar tissue that forms at the spinal cord injury (SCI) site can be categorized into "glial" and "fibrotic" components. The glial scar often refers to the astrogliotic region that surrounds the central core and prevents non-CNS cells (such as leukocytes) from invading the CNS parenchyma. The glial scar has been intensely studied for its role in inhibition of axon regeneration (Silver and Miller, 2004). However, much less is known about the fibrotic scar, which is typically characterized by excess deposition of extracellular matrix molecules. Most of our current knowledge comes from in vitro coculture assays of primary astrocytes and meningeal fibroblasts that mimic the astrocyte-fibroblast border that forms after SCI in vivo (Rudge and Silver, 1990; Shearer and Fawcett, 2001). When neurons are placed on top of this coculture, they prefer to grow over astrocytes and avoid fibroblasts, indicating that fibroblasts are less permissive or inhibitory to axon growth.

In vivo studies on the fibrotic scar have mostly used penetrating injuries that tear the dura and permit the invasion of meningeal fibroblasts into the lesion. However, penetrating injuries do not mimic most of the human cases of SCI, which are characterized as contusions that leave the dura intact. This raises the ques-

Received June 13, 2013; revised July 17, 2013; accepted July 23, 2013.

Author contributions: C.S., E. Blumenthal, E. Bray, K.K.P., P.T., and J.K.L. designed research; C.S., X.L., E. Blumenthal, E. Bray, K.L., J.R., V.K., C.L.-H., P.T., and J.K.L. performed research; C.S., E. Blumenthal, E. Bray, K.L., J.R., V.K., C.L.-H., P.T., and J.K.L. analyzed data; C.S., K.K.P., P.T., and J.K.L. wrote the paper.

This work was supported by NINDS 1R01NS081040-01, NINDS 1R21NS082835-01, U.S. Army W81XWH1010737, the Miami Project to Cure Paralysis, and the Buoniconti Fund. We thank Dr. David Brenner and Dr. Tatiana Kisseleva for donating the Col1 $\alpha 1$-GFP transgenic mice, Yadira Salgueiro for assistance with tissue processing, and Dr. Dario Motti for assistance with figure preparation. J.K.L. thanks Dr. Binhai Zheng in whose laboratory the preliminary data for this study were obtained.

The authors declare no competing financial interests.

Correspondence should be addressed to Dr. Jae K. Lee, University of Miami, Miami Project to Cure Paralysis, Department of Neurological Surgery, 1095 NW 14th Terrace, LPLC 4-19, Miami, FL 33136-1060. E-mail: JLee22@med.miami.edu.

DOI:10.1523/JNEUROSCI.2524-13.2013

Copyright $\odot 2013$ the authors $\quad 0270-6474 / 13 / 3313882-06 \$ 15.00 / 0$ tion of whether fibroblasts are even present at the injury site after clinically relevant contusion injuries and are even worth considering as therapeutic targets to promote axon regeneration. Previous electron microscope studies of rodent spinal cord contusion sites have alluded to the presence of fibroblast or fibroblast-like cells (Zhang et al., 2005; Kostyk et al., 2008), but there are almost no reports on the origin, prevalence, or the spatiotemporal distribution of fibroblasts in the contusion site.

One reason for this gap in knowledge is the technical difficulty of identifying proper markers of fibroblasts. The commonly used marker fibronectin typically labels extracellular matrix molecules rather than cell bodies, and other cells, such as macrophages, may also secrete fibronectin at the injury site (Yamauchi et al., 1987). Indeed, it is widely accepted that there is not a single marker for all fibroblasts (Kalluri and Zeisberg, 2006). To overcome this technical hurdle, we used transgenic mice in which GFP is expressed under the control of the collagen $1 \alpha 1$ promoter (Coll $\alpha 1$ GFP mice) (Yata et al., 2003). We describe, for the first time, a robust distribution of fibroblasts in the injury site after contusive SCI and conclude that these fibroblasts are of perivascular origin.

\section{Materials and Methods}

Animals. Col1 $\alpha 1$-GFP mice were kindly donated by Dr. David Brenner, University of California San Diego, La Jolla, CA (Yata et al., 2003). NG2CreER transgenic mouse was obtained from The Jackson Laboratory (stock 008538, Zhu et al., 2011). Rosa26-tdTomato reporter mice were kindly donated by Dr. Fan Wang, Duke University, Durham, NC (Lee et al., 2009). All mice had pure C57BL/6 genetic background. To generate Col $1 \alpha 1 / \mathrm{NG} 2$ mice for genetic lineage tracing studies, the three mouse lines were bred to each other to produce Col $1 \alpha 1-\mathrm{GFP}^{+} / \mathrm{NG}-\mathrm{CreER}{ }^{+} / \mathrm{Rosa} 26-$ tdTomato $^{\mathrm{fl} /+}$ offspring. Coll $\alpha 1 / \mathrm{NG} 2$ mice (6-7 weeks old) received tamoxifen as previously described (Lee et al., 2009). One week after the last injection, mice were subjected to SCI. All animal procedures were approved by the University of Miami Institutional Animal Care and Use Committee.

Surgery. Seven- to 9-week-old female mice were anesthetized (ketamine/xylazine $100 \mathrm{mg} / 15 \mathrm{mg} / \mathrm{kg}$ i.p.) before receiving mid-thoracic (T8) spinal cord injuries. Dorsal hemisections were performed as previ- 

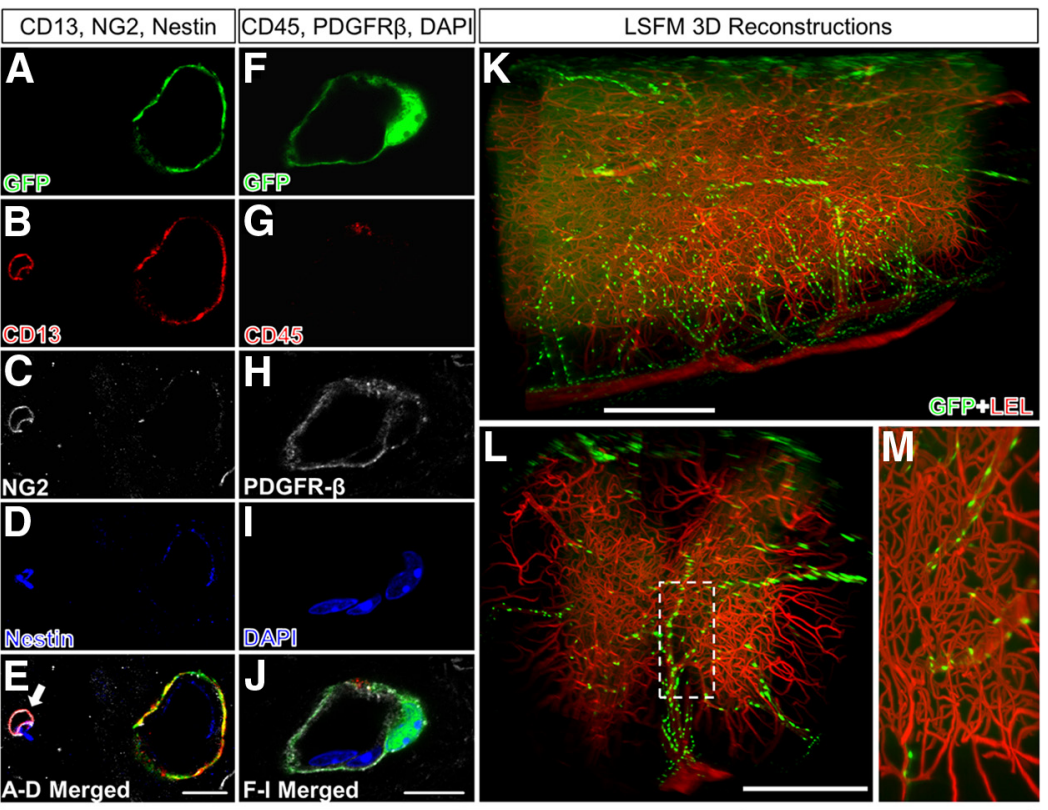

\begin{tabular}{|l|l|c|}
\hline \multicolumn{1}{|c|}{ Cell types } & \multicolumn{1}{|c|}{ Marker } & $\begin{array}{c}\text { Percent co-localization with } \\
\text { GFP }\end{array}$ \\
\hline Smooth muscle cells, myofibroblasts & aSMA & $0.00 \%$ \\
\hline Macrophages, microglia & CD11b, F4/80 & $0.00 \%$ \\
\hline Fibrocytes, leukocytes & CD45 & $0.00 \%$ \\
\hline Endothelial cells & Glut1, PECAM & $0.00 \%$ \\
\hline Astrocytes & GFAP & $0.00 \%$ \\
\hline Oligodendrocytes & Olig2 & $0.00 \%$ \\
\hline Pericytes: & CD13+nestin, CD13+NG2 & $0.00 \%$ \\
\hline (also NPCs, endothelial cells) & Nestin & $0.00 \%$ \\
\hline (also OPCs) & NG2 & $0.00 \%$ \\
\hline (also endothelial cells, vSMCs, fibroblasts) & CD13 & $78.70 \%$ \\
\hline (also most perivascular cells) & PDGFR- $\beta$ & $95.70 \%$ \\
\hline
\end{tabular}

Figure 1. Col1 $\alpha 1$-GFP ${ }^{+}$cells are preferentially associated with larger blood vessels and express CD13 and PDGFR- $\beta$ in uninjured spinal cord. Col $\alpha 1$-GFP ${ }^{+}$cells $(\boldsymbol{A}, \boldsymbol{F})$ express (D13 (B) and PDGFR- $\beta(\boldsymbol{H})$, but not NG2 (C), nestin (D), CD45 (G), or markers for fibrocytes, neural cells, or immune cells (pictures not shown). Table lists percentage of Col1 $\alpha 1$-GFP ${ }^{+}$cells that express each cell type-specific antigen. LSFM reconstructions of spinal vasculature (LEL, red) in Col1 $\alpha 1$-GFP mouse spinal cords show Col1 $\alpha 1^{+}$cells (GFP, green) along large spinal vessels but not microvessels $(\boldsymbol{K}-\boldsymbol{M})$. $\boldsymbol{E}$, Arrow refers to pericyte. Scale bars: $\boldsymbol{A}-\boldsymbol{J}, 10 \mu \mathrm{m}: K, \boldsymbol{L}, 500 \mu \mathrm{m}$.

ously described (Lee et al., 2010b). Moderate contusion injuries (75 $\mathrm{kDynes}$ ) were performed using the Infinite Horizon impactor device (Precision Systems and Instrumentation). Injured mice received lactated Ringer's solution, antibiotics (Baytril, $10 \mathrm{mg} / \mathrm{kg}$ ), and analgesics (buprenorphine, $0.05 \mathrm{mg} / \mathrm{kg}$ ) subcutaneously for the first week after surgery. Twice daily bladder expressions continued for the duration of the study.

Histology. At $0,3,4,5,7,14,28$, or $56 \mathrm{~d}$ after contusive SCI $(n=5$ per group) and at 3 or $14 \mathrm{~d}$ after dorsal hemisection ( $n=3$ per group), mice were perfused transcardially with $4 \%$ PFA. Brains and spinal cords were harvested and prepared for immunohistochemistry as previously described (Lee et al., 2010a). Serial sagittal cryosections $(10 \mu \mathrm{m})$ of the injury site were immunostained for $\alpha$-smooth muscle actin ( $\alpha \mathrm{SMA}$ )-Cy3 (Sigma), CD11b (Invitrogen), CD13 (Abcam), CD45 (eBioscience), F4/80 (AbD Serotec), fibronectin (Millipore), Glut1 (Millipore), GFAP (Invitrogen), GFP (Abcam), laminin (Sigma), nestin (Aves Laboratories), NG2 (Millipore), Olig2 (Millipore), PDGFR- $\beta$ (Abcam), PECAM/CD31 (BD Biosciences), RFP (Rockland), or 5-hydroxytryptamine (Immunostar) (Lee et al., 2010a). After primary antibody incubation, sections were incubated in the appropriate AlexaFluor secondary antibodies (Invitrogen).

Quantifications. Cell counts were performed by unbiased (to the experimental group) observers using the Nikon IS software. Cell density counts were performed at the injury epicenter and in two adjoining sections by obtaining the average of the number of Coll $\alpha 1$-GFP ${ }^{+}$cells in five randomly selected $100 \mu \mathrm{m} \times 100 \mu \mathrm{m}$ boxes in each tissue section. Colocalization was determined using Olympus FV10-ASW 3.0 viewer software to examine each of the ten $1 \mu \mathrm{m} z$-stack slices and counting the cells stained by a given antigenic marker (as listed above) colocalized with any Coll $\alpha 1-\mathrm{GFP}^{+}$cells.
Differences in cell number were tested using oneway ANOVA with Tukey's post test.

Tissue clearing and light sheet fluorescent microscopy (LSFM). To label spinal cord vasculature, Coll $\alpha 1$-GFP mice were transcardially perfused with DyLight-594-labeled Lycopersicon esculentum lectin (LEL) (Vector Laboratories) as previously described (Jahrling et al., 2009). Spinal cords were postfixed in $4 \%$ PFA and then washed in PBS (both overnight at $4^{\circ} \mathrm{C}$ ). The dura was removed and the spinal cord cut into 8-mm-long segment centered at T8. Samples were incubated (on a rotating shaker at room temperature) in $50 \%, 80 \%$, $100 \%$ tetrahydrofuran (Sigma 401757) each for $2 \mathrm{~h}$, and then $100 \%$ tetrahydrofuran overnight. The next day, samples were transferred to BABB solution (1:2 ratio of benzyl alcohol, Sigma, 305197; and benzyl benzoate, Sigma, B6630) for 2.5-3 h. After clearing, samples were immediately imaged by LSFM (Ultramicroscope, LaVision BioTec). Image analysis and $3 \mathrm{D}$ reconstructions were performed using Imaris (Bitplane), and consecutive serial view movies were created in Image (National Institutes of Health).

\section{Results \\ Col1 $\alpha 1^{+}$cells in the uninjured spinal cord}

To obtain an accurate view of the Coll $\alpha 1$ cells and blood vessels in the uninjured spinal cord, we labeled the endothelial cells of the circulatory system (via transcardial perfusion) with LEL. After making the spinal cord transparent, we used LSFM to obtain optical sections of the entire specimen. 3D reconstructions (Fig. $1 K-M$ ) as well as consecutive serial views of the image stack (400-500 optical sections) clearly demonstrate that Col $1 \alpha 1^{+}$cells reside along blood vessels throughout the spinal cord. The most visible regions were along large-diameter vessels. Coll $\alpha 1^{+}$cells were also visible along arterioles and venules with a minor population observed on microvessels. To obtain a more detailed histological profile of the Coll $\alpha 1^{+}$cells, we performed immunohistochemistry on spinal cord sections using antibodies against smooth muscle $(\alpha \mathrm{SMA})$ and basal lamina (laminin); $60.9 \pm 5.1 \%$ of Coll $\alpha 1^{+}$cells were found surrounding smooth muscle cells indicative of arterioles with laminin expression on their abluminal surfaces.

To further identify the cellular identity of Coll $\alpha 1^{+}$cells, we obtained an antigenic profile using a comprehensive list of cellular markers as listed in Figure 1. Because pericytes are the prototypical perivascular cells, we focused on whether Coll $\alpha 1^{+}$cells expressed pericyte markers. Although there are many pericyte markers referenced in the literature, no single markers are considered specific for this cell type (Armulik et al., 2011). Therefore, we chose colabeling of CD13/NG2 or CD13/nestin as our pericyte markers based on previous immunoelectron microscopy studies that identified CD13 (Kunz et al., 1994), NG2 (Schlingemann et al., 1990), and nestin (Alliot et al., 1999) as antigens expressed by pericytes. Although $78.7 \%$ of Coll $\alpha 1^{+}$cells expressed CD13, none expressed NG2 or nestin (Fig. $1 A-E$ ). PDGFR- $\beta$ and $\alpha$ SMA are also commonly used markers of pericytes (Armulik et al., 2011). No Coll $\alpha 1^{+}$cells expressed $\alpha$ SMA. Although most 

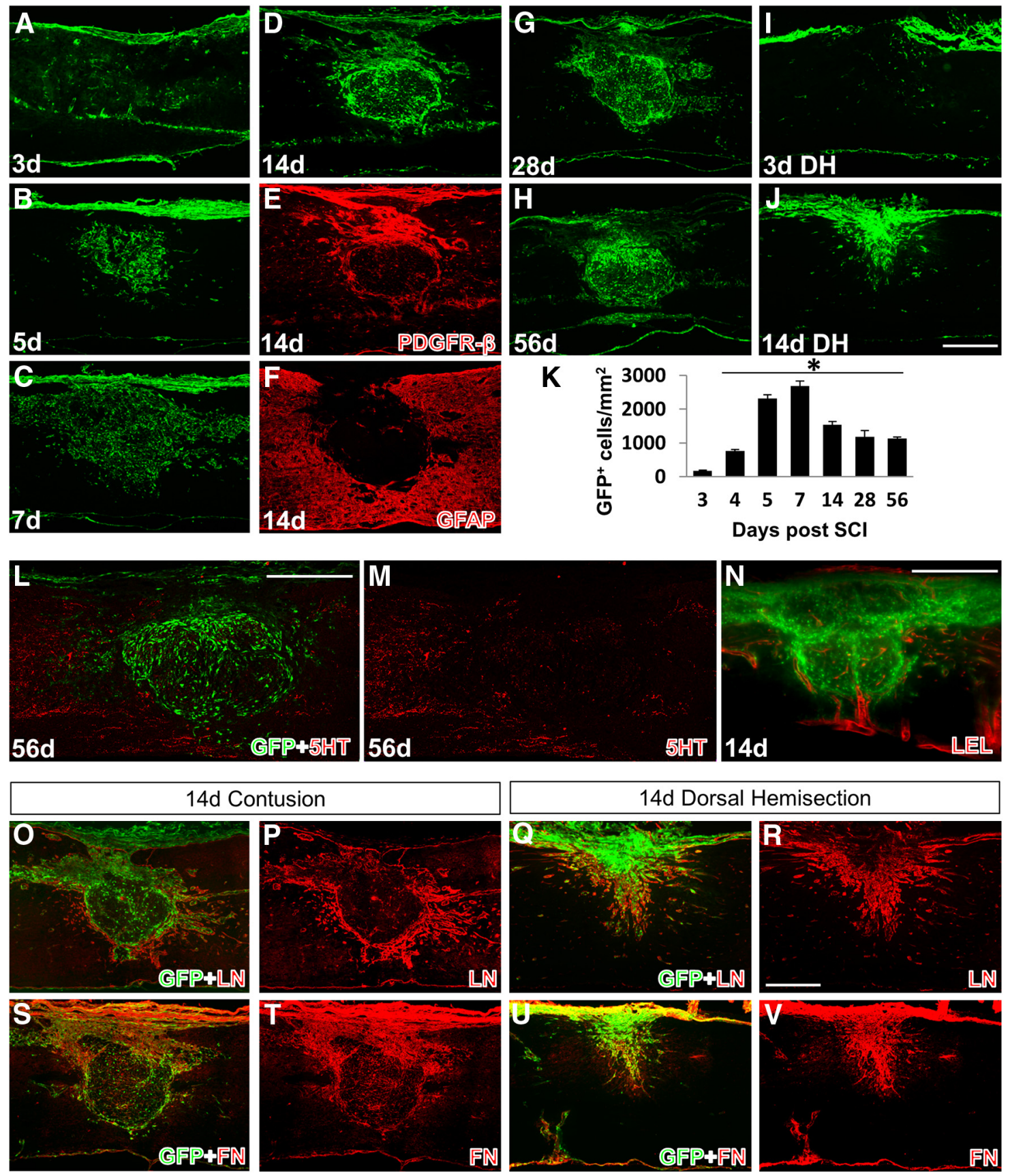

Figure 2. Spatiotemporal distribution of Col1 $\alpha 1-\mathrm{GFP}^{+}$cells after SCI. Col1 $\alpha 1-\mathrm{GFP}^{+}$cells enter the injury site between 3 and $5 \mathrm{dpi}(\boldsymbol{A}, \boldsymbol{B})$ and persist chronically $(\boldsymbol{C}-\boldsymbol{H})$. The cell density is highest at $7 \mathrm{dpi}(\boldsymbol{C}, \boldsymbol{K})$ and by $14 \mathrm{dpi}(\boldsymbol{D})$ condense into a fibrous scar that apposes to the GFAP ${ }^{+}$astrocytic scar $(\boldsymbol{F})$ and are the predominant PDGFR- $\beta^{+}$cells in the scar $(\boldsymbol{E})$. Serotonin $(5 \mathrm{HT})$ axons fail to penetrate the Col1 $\alpha 1$-GFP ${ }^{+}$region $(\boldsymbol{L})$. $\boldsymbol{M}$, Red channel in $\boldsymbol{L}$. After dorsal hemisection, $\left(\mathrm{Cl} 1 \alpha 1^{+}\right.$cells also do not enter the injury site until after $3 \mathrm{dpi}(\boldsymbol{I})$ and fill the injury epicenter by $14 \mathrm{dpi}(\boldsymbol{J})$. LEL-labeled vasculature (red) encloses the fibrotic scar along the dense peripheral rim of Col1 $\alpha 1$-GFP ${ }^{+}$cells. $\boldsymbol{N}$, a single LSFM section. $\mathbf{0}-\boldsymbol{V}$, Representative images of laminin (LN) and fibronectin (FN) expression relative to Col1 $\alpha 1^{+}$cells in the scar. ${ }^{*} p<0.0001$ (one-way ANOVA). Scale bars: $A-J, L-V, 500 \mu \mathrm{m}$.

Col $1 \alpha 1^{+}$cells expressed PDGFR- $\beta$ (95.7\%), PDGFR- $\beta$ was also expressed by other cells located adluminal to Col $1 \alpha 1^{+}$cells, suggesting that PDGFR- $\beta$ is a marker for multiple types of perivascular cells (Fig. $1 F, H, J$ ). Col $1 \alpha 1^{+}$cells did not express markers for endothelial cells (PECAM, Glut1), macrophages/microglia (CD11b, F4/80), fibrocytes/leukocytes (CD45), or neural cells (GFAP, Olig2) (Fig. 1). Therefore, based on the histological location of Coll $\alpha 1^{+}$cells preferentially around larger-diameter blood vessels and their antigenic profile, our results indicate that Col $1 \alpha 1^{+}$cells are predominantly perivascular fibroblasts in the uninjured spinal cord.
Col1 $\alpha 1^{+}$cells after SCI

To investigate the contribution of $\operatorname{Col} 1 \alpha 1^{+}$cells to the formation of the fibrotic scar after SCI, we performed mid-thoracic contusive SCI on Coll $\alpha 1$-GFP mice and histologically assessed the injury site at multiple time points after injury. At $3 \mathrm{~d}$ postinjury (dpi), the injury site contained mostly necrotic tissue, with Col $1 \alpha 1^{+}$cells still mostly attached to blood vessels (Fig. $2 A$ ). Col $1 \alpha 1^{+}$cells started to accumulate at the injury site $4 \mathrm{dpi}$, and by day 5 there was a visible mass of Coll $\alpha 1^{+}$cells at the injury epicenter (Fig. $2 B$ ). The density of Coll $\alpha 1^{+}$cells reached its peak at $7 \mathrm{~d}$ when the entire injury site (GFAP-negative area) was homoge- 


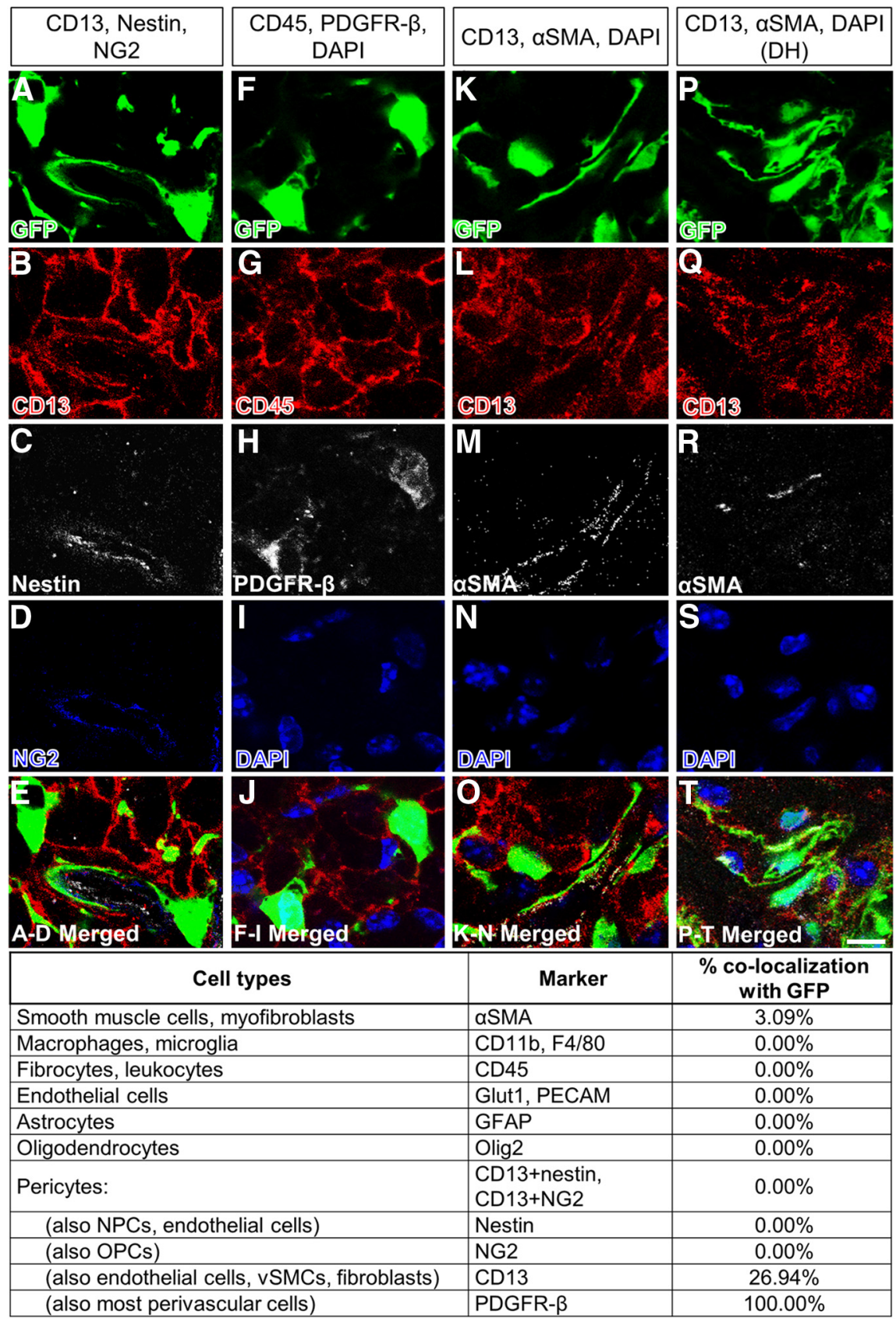

Figure 3. Antigenic profile of Col $1 \alpha 1$-GFP ${ }^{+}$cells at 14 dpi. Col $1 \alpha 1-$ GFP $^{+}$cells $(\boldsymbol{A}, \boldsymbol{F}, \boldsymbol{K})$ continue to express PDGFR- $\beta(\boldsymbol{H})$ after contusive SCI $(\boldsymbol{A}-\mathbf{O})$. A smaller percentage of cells continue to express CD13 $(\boldsymbol{B}, \boldsymbol{L})$. MostCol1 $\alpha 1-\mathrm{GFP}^{+}{ }^{+}$cells expressed $\alpha$ SMA at 5 dpi (data not shown) but decrease to $\sim 3 \%$ by $14 \mathrm{dpi}(\boldsymbol{M})$. Similar $\alpha$ SMA expression was observed after dorsal hemisection (DH) $(\boldsymbol{P}-\boldsymbol{T})$. Table lists percentage of Col1 $\alpha 1-$ GFP ${ }^{+}$cells that express each cell type-specific antigen after contusive SCI. Scale bar, $10 \mu \mathrm{m}$. thoracic level. Similar to contusive SCI, at $3 \mathrm{~d}$ after dorsal hemisection, Coll $\alpha 1^{+}$ cells were not observed at the injury site (Fig. 2I). At $14 \mathrm{~d}$ after dorsal hemisection, in contrast to the contusive SCI described above, Coll $\alpha 1^{+}$cells completely filled the fibrotic scar and seemed to form a continuous fibrous tissue with the overlying dura, suggesting a meningeal origin (Fig. $2 J)$. Fibronectin expression closely matched the distribution of Coll $\alpha 1^{+}$cells in both types of injuries (Fig. $2 S-V$ ). Laminin expression was strong around the peripheral rim of the injury site after contusion, whereas it was expressed throughout the injury site after dorsal hemisection (Fig. $2 O-R)$. Therefore, although the time course of Coll $\alpha 1^{+}$cells accumulating at the injury site seems to be similar between the two injury types, the cellular distribution of Coll $\alpha 1^{+}$cells in the fibrotic scar after contusive SCI, in which the dura remains intact, is significantly different compared with dorsal hemisection SCI in which the dura is torn.

To identify possible changes in the cellular identity of Coll $\alpha 1^{+}$cells after contusive SCI, we used the same list of antibodies described above to obtain an antigenic profile in the injured spinal cord. At all acute and chronic time points examined, all Coll $\alpha 1^{+}$cells expressed PDGFR- $\beta$ (100\%) (Fig. $3 F, H$ ) and most PDGFR- $\beta$ cells in the fibrotic scar were Coll $\alpha 1^{+}$(Fig. 2E), indicating that Coll $\alpha 1^{+}$cells are the predominant PDGFR- $\beta$-expressing cells at the fibrotic scar. Whereas $78.7 \%$ of Coll $\alpha 1^{+}$cells expressed CD13 in the uninjured spinal cord (Fig. 1), this number decreased to $26.9 \%$ in the fibrotic scar by $14 \mathrm{dpi}$ (Fig. $3 \mathrm{~K}, L$ ), indicating that either Coll $\alpha 1^{+}$cells at the fibrotic scar lost CD13 antigenicity and/or other cell types that do not express CD13 contributed to the Coll $\alpha 1^{+}$cell population in the fibrotic scar. Also, although Col $1 \alpha 1^{+}$cells did not express $\alpha$ SMA before injury, some of them transiently expressed $\alpha$ SMA acutely after injury; this coexpression peaked at $5 \mathrm{dpi}$ and de- neously filled with Coll $\alpha 1^{+}$cells (Fig. 2C). The size of the fibrotic scar decreased by $14 \mathrm{~d}$, with Coll $\alpha 1^{+}$cells displaying a heterogeneous distribution pattern; the peripheral border adjacent to the astroglial scar contained a dense rim of Coll $\alpha 1^{+}$cells (Fig. $2 D, F$ ), whereas the inner region contained Coll $\alpha 1^{+}$cells that were interspersed between macrophages at a much lower density. Although this general distribution pattern continued at 28 and 56 dpi (Fig. $2 G, H)$, the morphology of Coll $\alpha 1^{+}$cells continues to change over this period to become increasingly elongated. In addition, Col $1 \alpha 1^{+}$ cells formed a tight border with astrocytes and appeared to form a barrier against serotonin axon regeneration (Fig. $2 L, M$ ).

To compare contusive and penetrating injuries in the Col $1 \alpha 1$ GFP mice, we performed a dorsal hemisection at the same mid- creased by 7 dpi, reaching $\sim 3.09 \%$ by $14 \mathrm{dpi}$ (Fig. 3 ). However, as in the uninjured spinal cord, Coll $\alpha 1^{+}$cells did not express markers for any other cells types, including microglia/macrophages, astrocytes, and endothelial cells (Fig. 3), which makes it unlikely that other cell types began to express Coll $\alpha 1$ in response to injury or that cells in addition to these $\operatorname{Col} 1 \alpha 1^{+}$fibroblasts (and macrophages) contribute to the fibrotic scar. Similar expression pattern of CD13 and aSMA was observed after dorsal hemisection (Fig. $3 P-T$ ). Therefore, our results indicate that Coll $\alpha 1^{+}$cells begin to enter the injury site at $\sim 3-4 \mathrm{~d}$ after SCI and are a major component of the fibrotic scar. In addition, Col $1 \alpha 1^{+}$cells are the predominant PDGFR- $\beta$-expressing cells in the fibrotic scar. 
Col $1 \alpha 1^{+}$cells originate mostly from blood vessels after SCI

Although Coll $\alpha 1^{+}$cells are present around blood vessels in the uninjured spinal cord, they are also present in the dura as meningeal fibroblasts (data not shown). Because the dura remains intact after a contusive SCI, we reasoned that the source of the Coll $\alpha 1^{+}$cells in the fibrotic scar was most likely the spinal vasculature rather than the dura. In addition, SCI in which the dura is torn (e.g., dorsal hemisection) leads to a completely different scar phenotype (Fig. 2I,J). To further investigate the source of the Coll $\alpha 1^{+}$cells, we used LSFM to obtain serial optical sections of the entire injury site from Col1 $\alpha 1$-GFP mice with blood vessels labeled with LEL (Supplemental Videos 3 and 4). Serial sections through the entire width of the spinal cord revealed Coll $\alpha 1^{+}$ cells unwrapping from blood vessels and forming a trail toward the fibrotic scar. In addition, the major vascular branches from the anterior and posterior vessels were always observed enclosing the fibrotic scar along the dense peripheral rim of Coll $\alpha 1^{+}$cells (Fig. 2N). Trails of Coll $\alpha 1^{+}$cells were also observed from the dorsal overlying dura. Although most of these cells were associated with blood vessels originating from the dura, many cells just underneath the dura appeared similar to Coll $\alpha 1^{+}$cells after dorsal hemisection, indicating that this minor population could have migrated through micro-tears and/or degraded basement membrane. Therefore, our results indicate that, although the dorsal-most portion of the fibrotic scar could be derived from meningeal Coll $\alpha 1^{+}$cells, most of the fibrotic scar is Coll $\alpha 1^{+}$cells of perivascular origin.

\section{Col1 $\alpha 1^{+}$fibroblasts are distinct from NG2 ${ }^{+}$pericytes}

Although collagen expression is normally unique to fibroblasts, pericytes have also been reported to express collagen after injury in other organs (Lin et al., 2008). To investigate whether collagenexpressing pericytes contribute to the population of Coll $\alpha 1^{+}$ cells in the fibrotic scar, we performed genetic fate mapping using NG2-CreER/Rosa26-tdTomato mice bred to Coll $\alpha 1$-GFP mice (referred as Col1 $\alpha 1 / \mathrm{NG} 2$ mice). Although NG2 ${ }^{+}$cells are commonly referred to as oligodendrocyte progenitor cells (OPCs), NG2 also labels pericytes. In these mutant mice, Col1 $\alpha 1^{+}$cells are always labeled green (with GFP), whereas $\mathrm{NG}_{2}{ }^{+} \mathrm{OPCs}$ and pericytes are labeled red (with tdTomato) only upon tamoxifen administration. Pericytes can be distinguished from OPCs by their tubular structure around blood vessels that are easily identified from 3D reconstructions.

Because tamoxifen-labeled NG2 cells and their entire progeny are permanently labeled with tdTomato, any $\mathrm{NG}^{+}{ }^{+}$cells that also express Col $1 \alpha 1$ should be colabeled with red and green fluorescence. However, it should be noted that only a fraction of $\mathrm{NG2}^{+}$ pericytes are labeled in these transgenic mice (Zhu et al., 2011). Before performing SCI, we waited $7 \mathrm{~d}$ after the last tamoxifen injection to allow tamoxifen to be fully metabolized and cleared from the body so that recombination would not be induced inadvertently in other cell types. Red perivascular NG2 ${ }^{+}$cells were found mostly around microvessels that typically branched from larger vessels surrounded by green Coll $\alpha 1^{+}$cells (Fig. $4 A-H$ ). This is consistent with our observation above that $\operatorname{Col} 1 \alpha 1^{+}$cells are preferentially around larger vessels and not on microvessels where pericytes are typically located.

To determine whether $\mathrm{NG}_{2}{ }^{+}$pericytes express Coll $\alpha 1$ in the fibrotic scar after SCI, we performed contusive SCI on Coll $\alpha 1 /$ NG2 mice and analyzed the injury site at 7 (data not shown) and $14 \mathrm{~d}$ after SCI (Fig. 4I-L). Whereas Coll $\alpha 1^{+}$cells filled the injury epicenter as described above, $\mathrm{NG}^{+}{ }^{+}$cells were located mostly outside of this region, indicating that $\mathrm{NG}_{2}{ }^{+} \mathrm{OPCs}$ and pericytes are not a major source of the fibrotic scar. Importantly, red $\mathrm{NG}^{+}$cells did not express Coll $\alpha 1$ (green fluorescence) with very rare exceptions. Therefore, our results indicate that NG2 ${ }^{+}$ pericytes do not make significant contributions to the $\operatorname{Col} 1 \alpha 1^{+}$ cell population that forms the fibrotic scar after SCI.

\section{Discussion}

The cellular origin of the fibrotic scar after CNS injury has traditionally been thought to be meningeal cells surrounding the brain and spinal cord. Therefore, virtually all previous investigations of the fibrotic scar after SCI have used models of penetrating injuries in vivo or primary cultures of meningeal cells in vitro. However, our data indicate an alternative source of the fibrotic scar, namely, Coll $\alpha 1^{+}$cells that reside in the perivascular space in the spinal cord. Even after a contusive model of SCI where the dura 
remains largely intact, $\mathrm{Col} 1 \alpha 1^{+}$cells constitute a significant portion of the fibrotic scar. Interestingly, there is a delay of several days before a significant number of Coll $\alpha 1^{+}$cells start to accumulate at the injury site, and these cells continue to alter their spatial distribution pattern through the first 2 weeks after injury. Consistent with previous descriptions of the fibrotic scar, Col $1 \alpha 1^{+}$cells form a distinct boundary with the astroglial scar (Bundesen et al., 2003) and appear as a barrier to axon regeneration.

What is the cellular identity of these perivascular Coll $\alpha 1^{+}$ cells? We focused on perivascular fibroblasts and pericytes as the most likely candidates for the identity of Coll $\alpha 1^{+}$cells and used multiple experimental strategies to address this question. Using LSFM and a comprehensive list of antibodies, we determined that Col $1 \alpha 1^{+}$cells are mostly PDGFR- $\beta^{+} / \mathrm{CD}_{13}{ }^{+}$cells that are located preferentially around larger-diameter blood vessels in the normal spinal cord. Also, we performed genetic fate mapping studies using Coll $\alpha 1 / \mathrm{NG} 2$ transgenic reporter mice to determine that $\mathrm{NG}^{+}$pericytes do not express Col $1 \alpha 1$ after SCI. Col $1 \alpha 1^{+}$ cells are around larger-diameter blood vessels, whereas NG2 ${ }^{+}$ pericytes are located mostly around capillaries that branch from $\operatorname{Col} 1 \alpha 1^{+}$vessels. Together, our data indicate that $\operatorname{Col} 1 \alpha 1^{+}$cells display characteristics of perivascular fibroblasts and not pericytes. However, it is important to note that our transgenic mice may label only a subset of all Coll $\alpha 1^{+}$cells.

A recent study reported GLAST ${ }^{+}$pericytes to be the source of the fibrotic scar after a penetrating SCI (Goritz et al., 2011). Both pericytes and fibroblasts are loosely defined cell types, thereby making the distinction between the two inherently difficult (Krueger and Bechmann, 2010). Goritz et al. (2011) described two types of pericytes, type A and B, that responded differently to injury. Type A pericytes, but not type B pericytes that were located adluminally, were the GLAST ${ }^{+}$cells that contributed to the fibrotic scar. This raises the possibility that our Col $1 \alpha 1^{+}$cells are the $\mathrm{GLAST}^{+}$type A cells, whereas adluminal cells, such as our $\mathrm{NG}_{2}{ }^{+}$pericytes, are the type B cells. Future studies are necessary to address this possibility. Nevertheless, our results indicate that Coll $\alpha 1^{+}$perivascular cells are the main source of the fibrotic scar and are consistent with the idea that the perivascular "niche" is an important source of the fibrotic scar (Goritz et al., 2011).

An interesting observation was that it took $\sim 5 \mathrm{~d}$ for $\operatorname{Col} 1 \alpha 1^{+}$ cells to significantly accumulate at the injury site. This was also true after a penetrating injury, suggesting that this is an active process by the Coll $\alpha 1^{+}$cells instead of simply being the result of shearing and invagination of the meninges from the injury. What are the molecular cue(s) that direct Coll $\alpha 1^{+}$cells to the center of the lesion? One possibility is that attractive cues from cells within the fibrotic scar, such as infiltrating immune cells, could be the mechanism by which Coll $\alpha 1^{+}$cells accumulate at the lesion core. In support of this hypothesis, previous studies have demonstrated that monocyte infiltration and TGF- $\beta$ production peak at $\sim 5-7 \mathrm{~d}$ after injury, which coincides with the large accumulation of Coll $\alpha 1^{+}$cells in our studies (Donnelly and Popovich, 2008).

In conclusion, we demonstrate that the Coll $\alpha 1$-GFP transgenic mouse is a novel in vivo model of fibrotic scar formation after SCI. Our data indicate that the fibrotic scar that forms in mice after both contusive and penetrating SCI is predominantly composed of Coll $\alpha 1^{+}$cells that migrate to the injury site from a perivascular source via a dynamic temporospatial process. Although we currently lack a definitive antigenic marker for fibroblasts, we provide strong evidence that the presence of Coll $\alpha 1^{+}$cells on larger-diameter blood vessels coupled with their PDGFR- $\beta^{+} / \mathrm{CD} 13^{+}$immunoreactivity defines these perivascular fibroblasts. A better understanding of the molecular signals drawing these perivascular fibroblasts to the fibrotic scar could have potential therapeutic implications for promoting axon regeneration after SCI.

\section{Notes}

Supplemental material for this article is available at http://www.jaeleelab. com/resources/jneurosci2013. Videos of 3D reconstructions and serial optical sections obtained from laser sheet fluorescent microscope. This material has not been peer reviewed.

\section{References}

Alliot F, Rutin J, Leenen PJ, Pessac B (1999) Pericytes and periendothelial cells of brain parenchyma vessels co-express aminopeptidase N, aminopeptidase A, and nestin. J Neurosci Res 58:367-378. CrossRef Medline

Armulik A, Genové G, Betsholtz C (2011) Pericytes: developmental, physiological, and pathological perspectives, problems, and promises. Dev Cell 21:193-215. CrossRef Medline

Bundesen LQ, Scheel TA, Bregman BS, Kromer LF (2003) Ephrin-B2 and EphB2 regulation of astrocyte-meningeal fibroblast interactions in response to spinal cord lesions in adult rats. J Neurosci 23:7789-7800. Medline

Donnelly DJ, Popovich PG (2008) Inflammation and its role in neuroprotection, axonal regeneration and functional recovery after spinal cord injury. Exp Neurol 209:378-388. CrossRef Medline

Göritz C, Dias DO, Tomilin N, Barbacid M, Shupliakov O, Frisén J (2011) A pericyte origin of spinal cord scar tissue. Science 333:238-242. CrossRef Medline

Jährling N, Becker K, Dodt HU (2009) 3D-reconstruction of blood vessels by ultramicroscopy. Organogenesis 5:227-230. CrossRef Medline

Kalluri R, Zeisberg M (2006) Fibroblasts in cancer. Nat Rev Cancer 6:392-401. CrossRef Medline

Kostyk SK, Popovich PG, Stokes BT, Wei P, Jakeman LB (2008) Robust axonal growth and a blunted macrophage response are associated with impaired functional recovery after spinal cord injury in the MRL/MpJ mouse. Neuroscience 156:498-514. CrossRef Medline

Krueger M, Bechmann I (2010) CNS pericytes: concepts, misconceptions, and a way out. Glia 58:1-10. CrossRef Medline

Kunz J, Krause D, Kremer M, Dermietzel R (1994) The 140-kDa protein of blood-brain barrier-associated pericytes is identical to aminopeptidase $\mathrm{N}$. J Neurochem 62:2375-2386. Medline

Lee JK, Case LC, Chan AF, Zhu Y, Tessier-Lavigne M, Zheng B (2009) Generation of an OMgp allelic series in mice. Genesis 47:751-756. CrossRef Medline

Lee JK, Chow R, Xie F, Chow SY, Tolentino KE, Zheng B (2010a) Combined genetic attenuation of myelin and semaphorin-mediated growth inhibition is insufficient to promote serotonergic axon regeneration. J Neurosci 30:10899-10904. CrossRef Medline

Lee JK, Geoffroy CG, Chan AF, Tolentino KE, Crawford MJ, Leal MA, Kang B, Zheng B (2010b) Assessing spinal axon regeneration and sprouting in Nogo-, MAG-, and OMgp-deficient mice. Neuron 66:663-670. CrossRef Medline

Lin SL, Kisseleva T, Brenner DA, Duffield JS (2008) Pericytes and perivascular fibroblasts are the primary source of collagen-producing cells in obstructive fibrosis of the kidney. Am J Pathol 173:1617-1627. CrossRef Medline

Rudge JS, Silver J (1990) Inhibition of neurite outgrowth on astroglial scars in vitro. J Neurosci 10:3594-3603. Medline

Schlingemann RO, Rietveld FJ, de Waal RM, Ferrone S, Ruiter DJ (1990) Expression of the high molecular weight melanoma-associated antigen by pericytes during angiogenesis in tumors and in healing wounds. Am J Pathol 136:1393-1405. Medline

Shearer MC, Fawcett JW (2001) The astrocyte/meningeal cell interface: a barrier to successful nerve regeneration? Cell Tissue Res 305:267-273. CrossRef Medline

Silver J, Miller JH (2004) Regeneration beyond the glial scar. Nat Rev Neurosci 5:146-156. CrossRef Medline

Yamauchi K, Martinet Y, Crystal RG (1987) Modulation of fibronectin gene expression in human mononuclear phagocytes. J Clin Invest 80:1720-1727. CrossRef Medline

Yata Y, Scanga A, Gillan A, Yang L, Reif S, Breindl M, Brenner DA, Rippe RA (2003) DNase I-hypersensitive sites enhance alpha1(I) collagen gene expression in hepatic stellate cells. Hepatology 37:267-276. CrossRef Medline 
Zhang SX, Geddes JW, Owens JL, Holmberg EG (2005) X-irradiation reduces lesion scarring at the contusion site of adult rat spinal cord. Histol Histopathol 20:519-530. Medline
Zhu X, Hill RA, Dietrich D, Komitova M, Suzuki R, Nishiyama A (2011) Age-dependent fate and lineage restriction of single NG2 cells. Development 138:745-753. CrossRef Medline 